\title{
Negative effects of bisphenol A on testicular functions in albino rats and their abolitions with Tribulus terristeris $L$.
}

\author{
Bushra Munir ${ }^{1,2}$, Abdul Qadir ${ }^{*}$, Mohammad Tahir ${ }^{2}$ \\ ${ }^{1}$ College of Earth and Environmental Sciences, University of the Punjab, Lahore, Pakistan, ${ }^{2}$ University of Health Sciences, \\ Khayaban-e-Jamia Punjab, Lahore, Pakistan
}

\begin{abstract}
This study was conducted to find out the ameliorative properties of Tribulus terristeris L (TT) on BPA induced spermatotoxicity in male albino rats. Mature male albino rats were divided into five groups, Group A was taken as control for comparison group, whereas the other four groups namely B(vehicle control), C (toxic), D (preventive control) and Group E (amelioration group) received distilled water, olive oil, BPA, TT, and (TT + BPA) respectively. Macroscopic results revealed decreased body weight of rats, weight of testes, and the relative tissue weight index (RTWI) in BPA induced group. Hormonal (testosterone) assay results revealed the decreased values of BPA treated group. Microscopic examination of testis of BPA treated rats showed reduction in leydig cells, decreased diameter of seminiferous tubules and low values of Johnsen's scoring. Histological examination showed discontinuity and irregularity of basement membrane and sloughing of the germinal cell linage. Group E showed the body weights of rats, weight of testes, RTWI, and increased, while reduced level of testosterone, reduced number of Leydig cells, decreased diameter of seminiferous tubules and low values of Johnsen's scoring were restored near to normal. These results demonstrate that TT might be beneficial in combating the spermatotoxicity, induced by BPA.
\end{abstract}

Keywords: Bisphenol A/negative effects. Tribulus terristeris L./properties. Spermatotoxicity. Testosterone.

\section{INTRODUCTION}

BPA (Bisphenol A) has been produced on large quantity all over the world since several decades and extensively used chemical in many products, such as dental sealants and thermal paper receipts, food packaging, epoxy resins, polycarbonate plastics, which are utilized in the numerous consumer products, manufacturing, water and food plastic containers, baby bottles and feeders, metal lining of beverage and food cans, medical tubing and dental fillings material (Kim et al., 2010). BPA residues were found in surface water, in fish tissues and can transfer from cans to food and from polycarbonate baby bottles to milk (Grumetto et al., 2008; Cao, Corriveau, Popovic, 2010; Wisniewski et al., 2015). It leaches from these products and consumed by boiling and microwaving procedures. Humans and animals may be exposed to BPA

\footnotetext{
*Correspondence: A. Qadir. College of Earth and Environmental Sciences, University of the Punjab, Quaid-e-Azam Campus, 54590, Lahore, Pakistan. E-mail: aqadir.cees@pu.edu.pk
}

through different routes, including ingestion, inhalation and dermal exposure. Ingestion or oral intake of food and water are the major exposure route in human being. It is reported that a human body is normally exposed to $10 \mu \mathrm{g} /$ day of BPA (Lagos-Cabré, Moreno, 2012)

BPA is a recognized endocrine disruptor with estrogenic activity. Initially it was produced as a synthetic estrogen which was used to enhance the rapid growth of poultry and cattle (Singh, Li, 2012). It mimics the natural estrogen in the body and interferes with the normal functions of endocrine system. It reduces the epididymal weight, testicular weight, testicular and epididymal sperm counts, plasma testosterone levels and it also main reason structural deformities of sperms in rodents (Al-Hiyasat, Darmani, Elbetieha, 2004). The oxidative stress induced by toxicant is the most common cause of damage to the sperm (Pasqualotto et al., 2000). It also causes early start of adolescence, birth defects, miscarriages, effects on ability to reproduce (Al-Hiyasat, Darmani, Elbetieha, 2004) breast cancer (Miao et al., 2008) and prostate cancer (Ho et al., 2006) diabetes, 
cardiovascular disorders and disrupt the metabolic processes (Lang et al., 2008).

Tribulus terrestris (TT) is an annual creeper weed belongs to the family Zygophyllaceae. It grows during summer season and has yellow flowers, thick spinous fruit and pinnately compound leaves (Philips, Mathew, Oriowo, 2006). It is native to tropical and temperate regions of Africa, Australia, and southern Asia. It is traditionally used as a tonic, aphrodisiac, antihypersensitive, astringent, analgesic, stomachic, urinary antiseptic and diuretic agent (Elahi, Asl, Shahian, 2013). So, it is used to diagnose the tumors, articular pains cardiovascular diseases, respiratory diseases as well as to cure diabetes (Karimi, Malekzadeh, Hoshmand, 2012). It is a completely natural herbal product available in market as powder, capsule, and tea. It contains biologically active substances including vitamins, flavonoids, steroids, spooning, alkaloids, unsaturated fatty acids and tannins (Saied, Darwish, 2015). Oral administration of the TT extract on animals clearly demonstrated spermatogonia proliferation and spermatogenesis stimulation that included spermatocytes and spetmatids' cell division (Elahi, Asl, Shahian, 2013). Experimental studies revealed that the TT extract increases the level of testosterone, which improve the sexual function in rats. Some clinical study has also confirmed that TT increases the testosterone levels to improve the male sexual vigor and develop the skeletal muscles (Gauthaman, Ganesan, 2008). The extract of TT has found no impacts on organs sensitivity to endocrine glands i.e. prostate and seminal vesicle in male rats (Martino et al., 2010). It is also used for the treatment of various other diseases such as cardiac edema, skin disorders, eye trouble and stones in bladder (Hussain et al., 2009).

A wide range of knowledge is available on BPA with reference to male reproductive toxicity, and generally these studies explain its impacts on spermatogenesis and testicular system through oxidative (Maamar et al., 2015; Yousaf et al., 2016). Keeping in view the deleterious effects of BPA on the reproductive health of human being, the present study was aimed to highlight the remedial effect of TT plant seed powder against BPA-induced spermetotoxicity in male Wister rats.

\section{MATERIAL AND METHODS}

Wister albino male adult rats $(n=40)$ aging $6-8$ weeks, having $150 \pm 10 \mathrm{~g}$ mass were procured and kept in the Experimental Research Laboratory, University of Health Sciences (UHS) Lahore. Prior to the experiment, thorough examination of the animals was carried out and they were weighed and then transferred into clean stainless steel cages under 12 hours light and dark cycle at $22 \pm$ $0.5^{\circ} \mathrm{C}$ with humidity $50 \%$. Rat pellets and water were used as a food for the normal rats during whole experiment. The body weight of rats was recorded at the initial stage and then weekly. Classification of rats was done into 5 groups (Group A, B, C, D and E) and there were 8 animals in each group. Animals present in the each of the groups were given a number by means of eosin solution (concentrated) on the dorsal part of their bodies and the identity was confirmed every time prior to an intervention. Bisphenol A (99.9\%) and olive oil of analytical grade were obtained from Sigma-Aldrich and Bulgarian Tribulus from Ultimate Nutrition, Inc. USA. Olive oil was used to dissolve BPA and double distilled water was used to dissolve TT. Each group was administrated with separate clean and sterilized utensils. In this experiment, Pyrex glassware were used rather than plastic lab wares to avoid plastic contamination of BPA during study. Glassware were washed with ethanol and double distilled water to minimize the procedural BPA contamination.

\section{Dosage and administration of drug}

Group 'A' used as control for comparison having deionized water only. Group ' $\mathrm{B}$ ' having olive oil $(0.2 \mathrm{ml} / \mathrm{animal} / \mathrm{day})$ only, served as vehicle control. Group ' $\mathrm{C}$ ' designated as the toxic group having BPA $(25 \mathrm{mg} / \mathrm{kg} /$ day $)$ dissolved in olive oil $(0.2 \mathrm{ml})$. Group 'D' served as preventive control having $20 \mathrm{mg} / \mathrm{kg} /$ day TT. Group ' $\mathrm{E}$ ' served as amelioration group having TT $(20 \mathrm{mg} / \mathrm{kg} /$ day $)$ in addition to treatment of group $\mathrm{C}$ and TT at the same time. The aforementioned dosages were given orally for four weeks and the quantity of BPA was selected by following the method given by Korkmaz et al. (2010) and Saied and Darwish (2015), whereas, TT dose was selected on the basis of recommendation of (Hussain et al., 2009) and for olive oil (Sangai, Verma, 2011). Rat was caught by catching its tail and then it was placed on the cage and lowered until the rat grasps the wire with its forefeet. Left hand's palm was placed on rat back holding the animal between the index finger and the thumb to prevent biting. Other fingers were comfortably placed around the body, out spreading as far down as it was possible and right hand was used for oral drug administration.

\section{Blood sampling for hormonal assay}

Each animal was weighed and then anesthetized with chloroform after 24 hours of last dose. Procedure 
of cardiac puncture was done using a disposable syringe to collect $5 \mathrm{ml}$ blood sample. and transferred to the vacutainer. After one hour, it was centrifuged at $3000 \mathrm{rpm}$ (EBA- 20 Hettich) for 15 minutes. Collection of clean and pure serum was done using a uncontaminated disposable dropper in a disposable plastic sterilized eppendorf tube for the analysis of Testosterone levels (hormonal analysis). Serum samples were then stored to $-20^{\circ} \mathrm{C}$ till the time of hormonal assay. Testosterone level was done using testosterone ELISA kit Biocheck, (USA).

\section{Dissection and tissue sampling}

A midline cut was made in the vertical manner reaching out from xiphoid to the pubic symphysis. Skin covering the abdomen alongside the muscles was horizontally reflected. The retractable testes were detached by pushing frontward into the body hole. Testes were then grossly examined for any abnormality, washed with normal saline and weighed. Testes of all rats were transversely sectioned from midline and submerged in Bouin's fixative for 24 hours (Bashir et al., 2009). After 24 hours, the pieces of testis were washed for 72 hours with changes of $50 \%$ and $70 \%$ ethanol to remove picric acid's yellow color. Then the processing of tissues was done in a usual way to dehydrate in ascending grades of alcohol $(50,70,80,90$ and $100 \%$ ), clearing by pure xylene and then impregnation in molten paraffin wax in an automatic processor of tissues "Histotech III-USA". Blocks of paraffin were formulated after using embedding station (Sakura Tissue-Tek ${ }^{\circledR}$ TECTM 5). These paraffin blocks were then cut into thin slices by utilizing the rotary microtome (Shandon, Finesse $\mathrm{ME}+$ ) for microtomy. Four micrometers broad sections were obtained which then were moved onto the clean surface of albumenized slide of glass for Haematoxylin and Eosin staining (Yousaf et al., 2016). The slides were dewaxed in xylene for staining; these were hydrated with different grades of alcohol (Bashir et al., 2009). After washing of slides with water, the section were treated with Haematoxylin solution to stain nuclei and immersed for separation in acidic alcohol, in Eosin, to stain cytoplasm. Then slides with testis sections were washed through a series of alcohol grades arranged in an ascending order, cleaned in xylene, and mounted in Dibutyl Phthalate Xylene (Bancroft, Gamble, 2008).

\section{Diameter of seminiferous tubules, Leydig cells count and scoring of the tubules}

Diameters of seminiferous tubules and Leydig cells were measured by Leica DM1000 microscope using
X10 and 40X objective with ocular micrometer after calibration. Johnsen's method was used to record and interpret the histological findings (Johnsen, 1970). This scoring method is ranged from 1 (tubular section without any cell) to 10 (tubular section with regular thickness of germinal epithelium with complete spermatogenesis stages (Saied, Darwish, 2015; Yousaf et al., 2016). The process of scoring was performed at X40 under microscope. The slide was moved in a zig-zag pattern to avoid overlapping.

\section{Statistical analysis}

Statistical Package for Social Sciences 18.0 was used to enter and examine the information of all the groups. The data was normally distributed and represented by mean and standard (Mean $\pm \mathrm{SD}$ ), median and lower and higher quartile (Table I). One-Way ANOVA was practiced to analyze the method for gross quantitative and histological parameters and group differences were confirmed by applying the Post Hoc Tukey test $(\mathrm{p}<0.01)$.

\section{RESULTS}

Throughout the period of experimentation, it was found that all the animals remained healthy and active. Their feeding habits were not altered and they reacted to different stimuli.

\section{Body weight of rats, weight of testes and RTWI}

Non-significant difference was observed in the body weights among all four groups of the rats (A, B, C, D and E) before experimental treatments, whereas, the final body weights variations of all treated rat groups were statistically significant at $\mathrm{P}(\mathrm{p}<0.001)$. A decrease in mean weight $(150.3 \pm 0.46)$ of the groups $\mathrm{C}$ (BPA treated group) was observed as compared to the control group $\mathrm{A}(\mathrm{p}<0.001)$. Group $\mathrm{E}$ (preventive group) showed that the mean final body weight $(243.4 \pm 4.2)$ increased as compared to the group $\mathrm{C}$ but near the weight of group A. Gross examination of the testes showed that there was no change in the shape, color and texture of the testes and any gross abnormalities.. Weight of testes $(1.5 \pm 0.22)$ and RTWI $(1.0 \pm 0.09)$ of group C showed significant $(\mathrm{p}<0.001)$ decrease as compared to control group A ( 2.5 $\pm 0.16)$ and $(1.2 \pm 0.08)$, respectively. No significant difference was observed between the groups $\mathrm{E}$ and that of group A, while the values of group E was close to the value that of control group (Table I). 
TABLE I - Showing mean initial, final weights of rats, mean paired weight of testes and relative tissue weight index among various groups

\begin{tabular}{|c|c|c|c|c|c|c|c|}
\hline Groups & Parameters & $\begin{array}{c}\text { Mean initial } \\
\text { body weight } \\
\text { of rats }(\mathrm{g}) \\
\end{array}$ & $\begin{array}{c}\text { Mean final } \\
\text { body weight } \\
\text { of rats }(\mathrm{g}) \\
\end{array}$ & $\begin{array}{c}\text { Mean paired } \\
\text { weight of } \\
\text { testes (g) } \\
\end{array}$ & $\begin{array}{c}\text { Relative tissue } \\
\text { weight index } \\
\text { (RTWI) } \\
\end{array}$ & $\begin{array}{c}\text { Mean diameter } \\
\text { of seminiferous } \\
\text { tubules }(\mu \mathrm{m})\end{array}$ & $\begin{array}{c}\text { Mean leydig } \\
\text { cell count }\end{array}$ \\
\hline \multirow{2}{*}{$\begin{array}{l}\text { Control } \\
(\mathrm{n}=8)\end{array}$} & Median & 150.5 & 233 & 2.5 & 1.2 & 239 & 13.3 \\
\hline & Range $\left(Q_{25}-Q_{75}\right)$ & $150.0-151.5$ & $222.0-252.0$ & $2.3-2.6$ & $1.2-1.3$ & $235.2-240.4$ & $12.9-13.3$ \\
\hline $\begin{array}{l}\text { Group B } \\
\text { (ehicle control) } \\
(\mathrm{n}=8)\end{array}$ & Range (Q25 - Q75) & $150.0-151.0$ & $231.0-248.0$ & $2.2-2.6$ & $1.2-1.4$ & $231.2-237.5$ & $11.0-13.9$ \\
\hline \multirow{3}{*}{$\begin{array}{l}\text { Group C (BPA } \\
\text { treated group) } \\
(\mathrm{n}=8)\end{array}$} & Mean \pm SD & $150.3 \pm 0.46$ & $200.8 \pm 40.88$ & $1.5 \pm 0.22$ & $1.0 \pm 0.09$ & $211.3 \pm 6.00$ & $7.2 \pm 0.48$ \\
\hline & Median & 150 & 195 & 1.6 & 1.0 & 210.1 & 7.2 \\
\hline & Range (Q25 - Q75) & $150.0-150.5$ & $171.5-227.0$ & $1.3-1.7$ & $1.0-1.1$ & $206.4-216.8$ & $6.8-7.6$ \\
\hline \multirow{3}{*}{$\begin{array}{l}\text { Group E } \\
\text { Amelioration } \\
\text { group TT and } \\
\text { BPA treated } \\
(\mathrm{n}=8)\end{array}$} & Mean \pm SD & $150.3 \pm 0.5$ & $243.4 \pm 4.2$ & $2.3 \pm 0.2$ & $1.2 \pm 0.1$ & $239.1 \pm 5.33$ & $13.3 \pm 0.46$ \\
\hline & Median & 150 & 243.5 & 2.3 & 1.2 & 238.5 & 13.4 \\
\hline & Range (Q25 - Q75) & $150.0-150.5$ & $242.5-245.0$ & $2.2-2.5$ & $1.1-1.2$ & $234.2-243.5$ & $13.0-13.7$ \\
\hline Significance & p-value & 0.899 & $0.003^{*}$ & $0.000^{*}$ & $0.004 *$ & $0.000 *$ & $0.000 *$ \\
\hline
\end{tabular}

* statistically significant p-value $\leq 0.05 . \mathrm{Q}_{25}=$ Lower Quartile, $\mathrm{Q}_{75}=$ Lower Quartile

\section{Histological examination}

The testes of rats demonstrated the histological features of testes in the groups A, B and D were normal with intact basement membranes of seminiferous tubules and all phases of spermatogenesis were found (Figure 1A,B,D). Close to the basement membrane, spermatogonia were observed. The primary spermatocytes with their prominent nuclei having dark colored stained chromatin material were also observed. Auxiliary spermatocytes rarely were observed on the grounds that they changed to spermatids immediately while spermatids were observed in both round and elongated stages. Seminiferous tubules' lumens were loaded with spermatozoa that had matured. The Leydig cells (These are polyhedral cells in shape having a prominent nucleus surrounded by pinkish cytoplasm) arranged in groups were demonstrated by interlobular tissue. Group C highlighted that the arrangement of the spermatogenesis was disturbed under the impact of the BPA and no mature sperms in the lumen but just debris was found (Figure 1C). The Leydig cells in the interlobular spaces were found decreased in their number. In a few animals, the sloughing of the germinal epithelium appeared. At some places, the basement membrane was also found disruptive. There was the restoration of the loss of the basement membrane in group E. All the spermatic lineage was present showed the complete process of spermatogenesis. There was no sloughing off and the lumen was full of the tails of mature spermatozoa. (Figure 1E).

\section{Diameter of seminiferous tubules, leydig cells count, Johnsen scoring of seminiferous tubules of the testes and testosterone level}

Micrometry for determining the diameter of seminiferous tubules $(211.3 \pm 6.00 \mu \mathrm{m})$ and Leydig cells count (7.2 \pm 0.48$)$ of group $C$ showed statistical significant difference in comparison with control group $\mathrm{A}(\mathrm{p}<0.001)$, whereas, no-significant difference among groups $\mathrm{A}(237.7$ $\pm 3.49 \mu \mathrm{m}$ and $13.2 \pm 0.59), \mathrm{B}(234.2 \pm 3.93 \mu \mathrm{m}$ and 12.6 $\pm 1.87), \mathrm{D}(237.1 \pm 3.48 \mu \mathrm{m}$ and $13.1 \pm 1.75)$ and $\mathrm{E},(239.1$ $\pm 5.33 \mu \mathrm{m} 13.3 \pm 0.46$ ), respectively (Table I). Johnsen's 

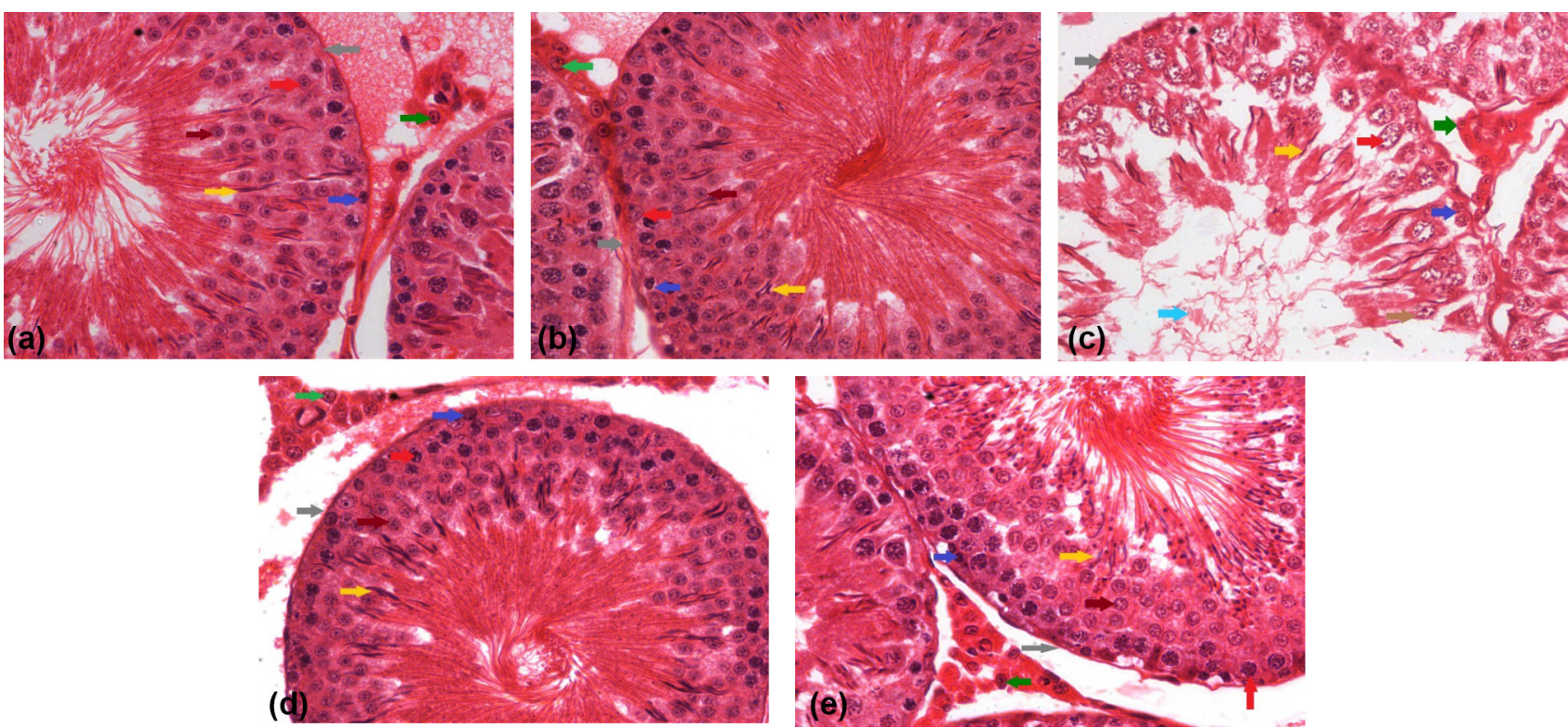

FIGURE 1 - Photomicrograph of testes in control group (a), Olive oil; vehicle control (b), BPA treated group (c), TT preventive control (d), and BPA+TT amelioration group (e) illustrating a seminiferous tubule having basement membrane (grey arrow), spermatogonia (blue arrow), primary spermatocytes (red arrow), round spermatid (maroon arrow) and mature spermatids (yellow arrow), Leydig cells (green arrow) present between the intertubular spaces (H \& E stain X400).

scoring for spermatogenesis showed statistical significant $(\mathrm{p}<0.001)$ deceased values of group $\mathrm{C}(5.55 \pm 0.15)$ when it was compare to control group A $(9.87 \pm 0.35)$. Group $\mathrm{E}(9.70 \pm 0.11)$ demonstrated significant improvement in Johnsen scoring as compared to the group C (Figure 2). Serum testosterone level showed significant $(\mathrm{p}<0.001)$ decreased levels of group $\mathrm{C}(0.95 \pm 0.50)$ as compared to rest of the groups A $(3.56 \pm 0.58), \mathrm{B}(3.56 \pm 0.58)$, $\mathrm{D}(0.72 \pm 0.69)$ and $\mathrm{E}(3.60 \pm 0.79)$ (Figure 3$)$.

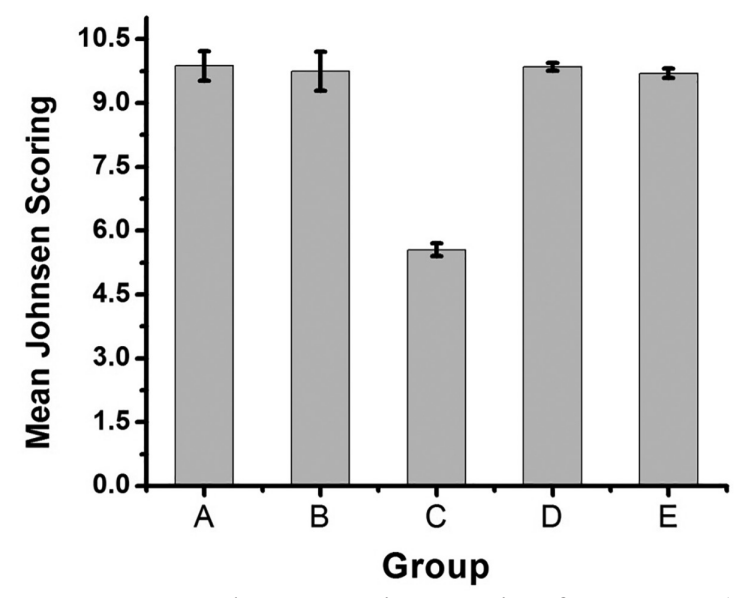

FIGURE 2 - Mean Johnsen scoring ranging from worst (1) to normal condition (10) of seminiferous tubules of the testes of rats among various groups viz; Group A (Control), Group B (Olive oil), Group C (BPA treated), Group D (TT plant powder) and Group E (BPA + TT plant powder).

\section{DISCUSSION}

Chemical pollution and reproductive health have a relation and always been a public health concern. Reproductive disorders with respect to male infertility are more common nowadays caused by BPA. It was reported that BPA was one of the important chemicals used as a monomer in of plastics synthesis and other products and have been detected in food and water consumed by

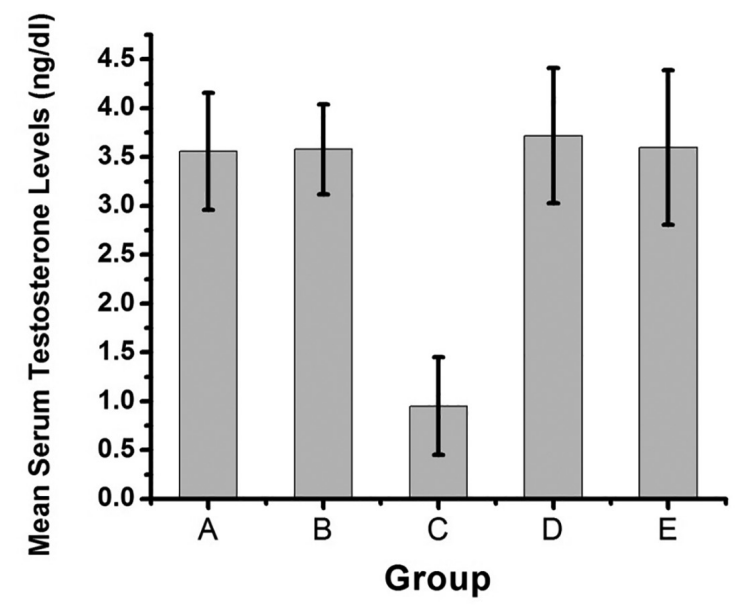

FIGURE 3 - Testosterone level $(\mathrm{ng} / \mathrm{ml})$ in various groups of rats viz; Group A (Control), Group B (Olive oil), Group C (BPA treated), Group D (TT plant powder) and Group E (BPA + TT plant powder). 
animals and Humans. Peretz et al. (2011) revealed that it reduce the production of estrogen and major cause of male infertility and oxidative stress. It is well documented that some endocrine disruptors like BPA are responsible to induce oxidative stress (El Ghazzawy et al., 2011). It was found that BPA lower significant level of $\mathrm{H}_{2} \mathrm{O}_{2}$, glutathione, superoxide dismutase (SOD), and lipid peroxidation synthesis, ultimately thus inducing oxidative stress associated with male infertility (Ghazzawy et al., 2011). TT has been used in China and India as an ayurvedic medicine for the treatment of various ailments and is prevalently claimed to improve sexual functions in men (Gauthaman, Adaikan, Prasad, 2002).

An dose of $25 \mathrm{mg} / \mathrm{kg}$ body weight BPA was selected, which is below toxic level because previous studies ( $50 \mathrm{mg}$ ) $\mathrm{kg}$ ), which can cause damage to reproductive system and to histological tissues. Changes in testicular histological features of testis are the indicators of environmental pollution resulted by BPA (Bhuiyan, Badrun, Quamrun, 2001; Saied, Darwish, 2015; Yousaf et al., 2016).

In present study male rats were exposed to BPA did not cause severe damage to histological features. In confirmation to our study, the same body weight of the BPA-administered rats was selected by Al-Hiyasat, Darmani and Elbetieha (2002). Gurmeet et al. (2014) indicated that the body weight of rats after exposure may slightly decrease compared to the control group because of stress. High dose of BPA (400 mg/kg) can significantly put the stress on rats resulting decrease in the weight of rats (Miao et al., 2008). Some studies have reported that the body weight of male rats did not show significant changes at low dose of BPA (Korkmaz et al. 2010; Norazit et al., 2012; Nanjappa, Simon, Akingbemi, 2012). In the TT treated group D the body weight of rats was slightly more than that of of Group $\mathrm{C}$ but lower than the control group. There was significant decrease in the combined weight of the testes in the BPA administered group when contrasted with the (control group A) which is the affirmation of testicular toxicity production and may be due to the inhibition of spermatogenesis, decreased elongated spermatids (Takahashi, Oishi, 2003). Some studies (Gupta, 2000; Takahashi, Oishi, 2003; Nanjappa, Simon, Akingbemi, 2012; Gurmeet et al., 2014) demonstrated that there were no consequences of BPA on combined weight of testes. The significant weight loss in testes could be recognized as the continuous exposure of BPA to the reproductive system and other organs (Kabuto, Simon, Akingbemi, 2004). The testicular weight reduction can be attributed as a result of reduction in the size of seminiferous tubules and spermatogenic cells. Karumari and Balasubramanian, (2014) reported similar results that in BPA- treated rat, testis revealed spermatogenic arrest in several seminiferous tubules causing abnormalities in spermatids formation and further found that testis revealed cellular changes like edema between the seminiferous tubules, scanty cellular components and wide empty lumen. Seminiferous epithelium height, tubular diameter, can also give information about testicular damage (Vendramini, Cerri, Miraglia, 2010), seminiferous diameter and height and Leydig cells count were recorded, and display highly significant reduction in all these items. BPA decrease the level of testosterone and reducing the diameter of seminiferous tubules, degeneration of germinal epithelial cells and aspermatogenesis (Norazit et al., 2012). BPA affects testicular functions in terms of Leydig cells. When treated with TT, combined weight of testes was observed to be increased when contrasted with the BPA prompted bunch. TT produce protective effect against BPA induces toxicity. This protective effect was seen in seminiferous diameter and Leydig cell count, this is attributed to the effect of TT on testis where it can stimulate the spermatogenesis and increase in the activity of Sertoli cells (Saied, Darwish, 2015). Our observations were in agreement to the work of (Gauthaman, Adaikan, Prasad, 2002) who assumed that the increased combined weight was because of androgenic impacts of TT that assume an imperative part in the development and separation of numerous tissues in addition to the organ of reproduction.

The current study showed that Johnsen scoring was 10 in control group. This scoring was dropped to 5-6 in BPA induced group indicating that neither spermatids nor spermatozoa are present but tubules contained spermatocytes. These finding are correlated with (Hutanu, 2011) who observed that the laboratory mice when treated with BPA showed disturbed spermatogenesis resulted in the reduction of production of sperms. Administration of TT had ameliorated effects on spermatotoxicity produced by BPA, evidenced by significant improvement in the mean Johnsen scoring in the group E (TT treated group). It was resulted that Johnsen scoring was increased 9-10 scores when treated with TT. (Bashir et al., 2009) observed the increase in the Johnsen scoring in the testes of prepubertal rats when treated with TT and credited this to an increase in the Luteinizing Hormone level which enhance production of sperms. Cek, Turan and Atik (2007) reported that the high dose of TT may change the histological response of the testes in treated groups and may induce excessive spermatogenesis and an increased number of spermatogenetic cysts.

Levels of serum testosterone were additionally discovered to be lesser in the rats treated with BPA (Group C) when contrasted with the control groups (A, 
B and D). These outcomes are similar to (Takahashi, Oishi, 2003) that demonstrated the results of testosterone was discernibly lower after BPA treatment and were enhanced again by the TT treatment of rats. The level of testosterone became higher in the treated group (Group E). Similar results were obtained by (Karimi et al., 2012) who additionally discovered that testosterone level increase might be due to the presence of protodioscin in the TT.

\section{CONCLUSION}

The present study showed that TT offers protection against BPA induced spermatotoxicity in albino rats. TT has the ability to reverse the changes that were induced by BPA in albino rat's testes. TT showed significant signs of restoration of the changes in body weights, testes weight and RTWI. Histological and biochemical parameters were improved near to normal. Present investigation also concluded that TT has significant role in remediation of BPA toxicity and opened a new avenue for the treatment of BPA toxicity in human with active compounds within TT.

\section{ACKNOWLEDGEMENTS}

We would like to thanks UHS to provide the facility for the experimental work and logistic support. We also extend our words of thanks to Prof. Dr. Safdar Ali Anwar and Ms.Um e-Aimen for reviewing the manuscript We are also grateful to Mr. Saqib Hussain, Mr. Rizwan Ali and Mr. Muhammad Faisal for technical support during experimental work.

\section{REFERENCES}

Al-Hiyasat AS, Darmani H, Elbetieha AM. Effects of bisphenol A on adult male mouse fertility. Eur J Oral Sci. 2002;110(2):163167.

Al-Hiyasat AS, Darmani H, Elbetieha AM. Leached components from dental composites and their effects on fertility of female mice. Eur J Oral Sci. 2004;112(3):267-272.

Bancroft JD, Gamble M. Theory and practical of histological techniques. $5^{\text {th }}$ ed. Edinburgh: Churchill Livingstone; 2008. $377 \mathrm{p}$.

Bashir A, Tahir M, Samee W, Munir B. Effects of Tribulus terrestris on testicular development of immature albino rats. Biomedica. 2009;25:63-68.
Bhuiyan AS, Badrun N, Quamrun N. Effects of Sumithion on the histological changes of spotted Murrel, Channa punctatus (Bloch). Pak J Biol Sci. 2001;4(10):1288-1290.

Cao, XL Corriveau J, Popovic S. Sources of low concentrations of bisphenol A in canned beverage products. J Food Prot. 2010;73(8):1548-1551.

Cek S, Turan F, Atik E. Masculinization of Convict Cichlid (Cichlasoma nigofasciatum) by immersion in Tribulus terrestris extract. Aquacult Int. 2007;15(2):109-119.

El Ghazzawy IF, Meleis AE, Farghaly EF, Solaiman A. Histological study of the possible protective effect of pomegranate juice on bisphenol-A induced changes of the caput epididymal epithelium and sperms of adult albino rats. Alexandria J Medic. 2011;47(2):125-137.

Elahi RK, Asl S, Shahian F. Study on the effects of various doses of Tribulus terrestris extract on epididymal sperm morphology and count in rat. Glob Veterin. 2013;10:13-17.

Gauthaman K, Adaikan PG, Prasad RN. Aphrodisiac properties of Tribulus terrestris extract (Protodioscin) in normal and castrated rats. Life Sci. 2002;71(12):1385-96.

Gauthaman K, Ganesan AP. The hormonal effects of Tribulus terrestris and its role in the management of male erectile dysfunction-an evaluation using primates rabbit and rat. Phytomedicine. 2008;15(1-2):44-54.

Ghazzawy IFE, Meleis AE, Farghaly EF, Solamain A. Histological study of the possible protective effect of pomegranate juice on bisphenol-A induced changes of the caput epididymal epithelium and sperms of adult albino rats. Alexandria J Med. 2011;47(2):125-137.

Grumetto L, Montesano D, Seccia S, Albrizio S, Barbato F. Determination of Bisphenol A and Bisphenol B residues in canned peeled tomatoes by reversed phase liquid chromatography. J Agric Food Chem. 2008;56(22):10633-10637.

Gupta C. Reproductive malformation of the male off spring following maternal exposure to estrogenic chemicals. Proc Soc Exp Biol Medic. 2000;224(2):61-68.

Gurmeet KSS, Rosnah I, Normadiah MK, Das S, Mustafa AM. Detrimental effects of Bisphenol A on development and functions of the male reproductive system in experimental rats. EXCLI J Exp. Clin. Sci. 2014;13:151-160. 
Ho SM, Tang WY, Frausto JB, Prins GS. Developmental exposure to estradiol and Bisphenol A increases susceptibility to prostate carcinogenesis and epigenetically regulates phosphodiesterase type 4. Cancer Res. 2006;66(1):5624-32.

Hussain AA, Mohammed AA, Ibrahim HH, Abbas AH. Study the biological activities of Tribulus terrestris extracts. Int J Chem Mol Nucl Mater Metallurgic Eng. 2009;3(9):510-512.

Hutanu D. Experimental investigations regarding the effects of Bisphenol A in adult mice spermatogenesis. Annals of RSCB. 2011;16(2):74-78.

Johnsen SG. Testicular biopsy score count- a method for registration of spermatogenesis in human testes: normal values and results in 335 hypogonadal males. Hormones. 1970;1(1):225.

Kabuto H, Amakawa M, Shishibori T. Exposure to Bisphenol A during embryonic/fetal life and infancy increases oxidative injury and causes underdevelopment of the brain and testis in mice. Life Sci. 2004;74(24):2931-2940.

Karimi JH, Malekzadeh SS, Hoshmand F. The effects of the Tribulus terrestris extract on spermatogenesis in the rat. J Jahrom Uni Med Sci. 2012;9(4):7-11.

Karumari J, Balasubramanian ES. Evaluation of antifertility potential of the Aqueous Extract of Ocimum sanctum (Linnaeus, 1767) leaves on the testicular histology of Rattus norvegicus Berkenhout (1769). Asian J Biochem Pharm Res. 2014;4(2):2029.

Kim JY, Han EH, Kim HG, Oh KN, Kim SK, Lee KY, Jeong HG. Bisphenol A-induced aromatase activation is mediated by cyclooxygenase- 2 up-regulation in rat testicular Leydig cells. Toxicol Lett. 2010;193(2):200-208.

Korkmaz A, Ahbab MA, Kolankaya D, Barlas N. Influence of vitamin $\mathrm{C}$ on bisphenol A nonylphenol and octylphenol induced oxidative damages in liver of male rats. Food Chem Toxicol. 2010;48(10):2865-2871.

Lagos-Cabré R, Moreno RD. Contribution of environmental pollutants to male infertily: a working model of germ cell apoptosis induced by plasticizers. Biol Res. 2012;45(1):5-14.

Lang IA, Galloway TS, Scarlett A, Henley WE, Depledge M, Wallace RB, Melzer D. Association of urinary Bisphenol A concentration with medical disorders and laboratory abnormalities in adults. JAMA. 2008;300(11):1303-10.
Maamar MB, Lesné L, Desdoits-Lethimonier C, Coiffec I, Lassurguère J, Lavoué V, Deceuninck Y, Antignac JP, Bizec BL, Perdu E, Zalko D, Pineau C, Chevrier C, Dejucq-Rainsford N, Mazaud-Guittot S, Jegou B. An investigation of the endocrinedisruptive effects of Bisphenol A in human and rat fetal testes. PLoS One. 2015;10(2):1-18.

Martino A, Anderson J, Morais RN, Spercoski KM, Rossi SC, Vechi MF, Golin M, Lombardi NF, Greca CS, Dalsenter PR. Effects of Tribulus terrestris on endocrine sensitive organs in male and female Wistar rats. J Ethnopharmacol. 2010;127(1):165-70.

Miao S, Gao Z, Kou Z, Xu G, Su C. Influence of Bisphenol A on developing rat estrogen receptors and some cytokines in rats: a two generational study. J Toxicol Environ Health. 2008;71(15):1000-1008.

Nanjappa MK, Simon L, Akingbemi BT. The industrial chemical Bisphenol A (BPA) interferes with proliferative activity and development of steroidogenic capacity in rat. Leydig cells. Biol Reprod. 2012;86(5):135.

Norazit A, Mohamad J, Razak SA, Abdulla MA, Azmil A. Effects of soya bean extract bisphenol A and 17 $\beta$-estradiol on the testis and circulating levels of testosterone and estradiol among peripubertal juvenile male sprague-dawley rats. Sains Malaysiana. 2012;41(1):63-69.

Pasqualotto FF, Sharma RK, Nelson DR, Thomas AJ, Agarwal A. Relationship between oxidative stress semen characteristics and clinical diagnosis in men undergoing infertility investigation. Fertil Steril. 2000;73(3):459-464.

Peretz J, Gupta RK, Singh J, Hernandez-Ochoa I, Flaws JA. Bisphenol A impairs follicle growth inhibits steroidogenesis and downregulates rate-limiting enzymes in the estradiol biosynthesis pathway. Toxicol Sci. 2011;119(1):209-217.

Philips OA, Mathew KT, Oriowo MA. Antihypertensive and vasodilator effects of the methanolic and aqueous extract of Tribulus terrestris in rats. J Ethnopharmacol. 2006;104(3):351355.

Saied NM, Darwish SK. A possible ameliorating effects of Tribulus terrestris on testicular dysfunction induced by xenoestrogens exposure in adult rats. Curr Sci Int. 2015;4(1):7389. 
Sangai NP, Verma JR. Quercetin alleviates Bisphenol A-induced changes in nucleic acid and protein contents in mice. Acta Pol Pharm. 2011;68(6):867-873.

Singh S, Li SS. Epigenetic effects of environmental chemicals bisphenol A and phthalates. Int J Mol Sci. 2012;13(8):1014310153.

Takahashi O, Oishi S. Testicular toxicity of dietary or parenterally administered Bisphenol A in rats and mice. Food Chem Toxicol. 2003;41(7):1035-1044.

Vendramini, Cerri ES, Miraglia SM. Amifostine reduces the seminiferous epithelium damage in Doxorubicin -treated prepubertal rats without improving the fertility status. Reproduc Bio Endocrinol. 2010;8:3-14.
Wisniewski, Romano RM, Kizys MML, Oliveira KC, Kasamatsu T, Giannocco G, Chiamolera MI, Silva MRDD. Romano MA. Adult exposure to bisphenol A (BPA) in Wistar rats reduces sperm quality with disruption of the hypothalamicpituitary-testicular axis. Toxicol. 2015;329:1-9.

Yousaf B, Liu G, Wang R, Qadir A, Ali MU, Kanwal Q, Munir B, Abbas Z. Bisphenol A exposure and healing effects of Adiantum capillus-veneris L plant extract (APE) in Bisphenol A-induced reproductive toxicity in albino rats. Environ Sci Pollut Res. 2016;23(12):645-657.

Received for publication on $30^{\text {th }}$ October 2016 Accepted for publication on $31^{\text {st }}$ January 2017 